\title{
LIBROS NUEVOS
}

\section{Reseñas}




\section{Alayón, Norberto (Organizador) (2005). Trabajo Social Latinoamericano: A 40 años de la reconceptualización. Buenos Aires, Argentina: Espacio Editorial ${ }^{1}$}

El libro incluye 21 artículos, pertenecientes a 26 autoras y autores de 18 países de América Latina, España y Portugal. Contiene textos de Norberto Alayón, Nora Aquín y Natalio Kisnerman de Argentina; Norah Castro de Bolivia; Vicente Faleiros y José Paulo Netto de Brasil; Jeanette Hernández y Omar Ruz de Chile; Liliana Torres de Colombia; Lorena Molina de Costa Rica; Odalys González de Cuba; Luis Araneda de Ecuador; Zoila Silva de El Salvador; Montserrat Feu de España; Tomasa De León de Guatemala; Lily Caballero de Honduras; Iris Prado y Martha Palacios de Nicaragua; Teresa Spalding de Panamá; Helena Reis y Cezarina Maurício de Portugal; Nilsa Burgos y Raquel Seda de Puerto Rico; Teresa Porzecanski de Uruguay; Egleé Vargas y Mairely Nuváez de Venezuela.

En la Introducción, Alayón plantea que puede ser útil preguntarnos para qué y por qué resulta pertinente escribir hoy, a casi cuarenta años de su aparición, acerca del Movimiento de Reconceptualización del Trabajo Social que se verificó en América Latina. El análisis de la historia de la profesión contribuye no sólo a develar la naturaleza misma de la disciplina, sino a entender también las propias particularidades de la profesión en la actualidad. Como en tantos otros aspectos de la vida misma, el presente es también -aunque no únicamente- la historia viva del pasado.

1 Este libro fue presentado por el Prof. Norberto Alayón y varias de las autoras, como parte de las actividades del VI Encuentro de Política Social y Trabajo Social, en la Ciudad de Panamá, del 5-8 de abril de 2005. La reseña presentada es la que está utilizando ESPACIO Editorial para la divulgación del libro. 
La significativa importancia que tuvo el proceso de Reconceptualización en el desarrollo del Trabajo Social latinoamericano, torna imprescindible y absolutamente actual la necesidad de recuperar el análisis del mismo, tanto en su génesis como en la influencia posterior que se verificó en la formación y en la práctica profesional de las y los trabajadores sociales.

De ahí la necesidad de seguir reflexionando sobre la Reconceptualización no por el simple regocijo de una especie de historicismo abstracto, sino para contribuir a dilucidar las posibilidades y los límites del Trabajo Social ante la gravedad de la situación social actual. Creemos que es este un modo de contribuir también a iluminar el presente de la profesión. Porque la Reconceptualización, entendida como reflexión y acción crítica, no ha desaparecido; de la misma manera que -a pesar de ser esta una época de marcado retroceso- tampoco han desaparecido los ideales por la vigencia de una sociedad y un mundo más libres y más justos. Porque la certeza de que las utopías de dignidad no han fenecido, mantiene la imperecedera llama que da fuerza a las luchas actuales y futuras en pos de los cambios deseados.

La participación de colegas de dieciséis paises de América Latina, le otorga al texto un modesto aire de "libro bolivariano", tanto por las afinidades de la "Patria Grande" frustrada, como por la aspiración inconclusa de la soberanía y la justicia social para nuestros pueblos. 